Research Article

\title{
Investigation of Modelling Approaches for Non-Linear Analysis of Reinforced Concrete Frames
}

\author{
Satish Paudel ${ }^{1, *}$ and Bikram Bhusal ${ }^{2}$ \\ ${ }^{I}$ School of Civil Engineering and Technology, Sirindhorn International Institute of Technology, Thammasat University, Thailand \\ ${ }^{2}$ Institute of Engineering, National College of Engineering, Tribhuvan University, Nepal
}

Received 17 September 2020; Accepted 20 October 2020

\begin{abstract}
This paper presents explicit evaluation of the safety and reliability of structures to obtain the actual performance of the structure numerically which will finally help designers to not only protect life, but also to minimize damage of the structures to an acceptable level. To do so, nonlinear finite element analysis of the frame is conducted, and results from lumped plasticity and continuum-based modelling approaches were compared with documented experimental results. The capability of each numerical model to capture the load deformation relationship and failure pattern is studied. Moreover, a parametric study is performed for selection of suitable material model which could depict the actual response of the frame for both considered numerical modelling tools. From this study, the analysis result of the lumped plasticity based model in SAP2000 was seen to be more realistic to the experiment result when the user-defined hinge model with confined nonlinear concrete property, non-linear rebar property with consideration of crack section as per the codal provision was performed. The frame remodeled with continuum mechanics based approach in LS-DYNA modelling tool could capture the experimental results with higher accuracy. In addition, among several material models available, Continuous surface cap model is recommended to be used for quasi-static analysis of structures since it can capture the performance of structure with significant accuracy.
\end{abstract}

Keywords: Non-linear static analysis, SAP2000, hinges, LS-DYNA, material models, seismic loading

\section{Introduction}

Inelastic behavior is inherent in most of the structures subjected to occasional lateral loading, so structural engineering has been adopting nonlinear static procedures for analyzing such structures. Development of several advance modelling tools for numerical analysis of structures has helped researcher to predict the complex non-linear behavior of R.C structural system numerically. Generally, lumped plasticity models, distributed plasticity models and continuum mechanics based models are implemented in modelling of the structures [1]. Although, assumptions and modelling aspects in first two approach is somehow approximate representation of structure with respect to linear or non-linear behavior rather than detailed 3D modelling as in continuum based approach, these approaches can also well capture the major performance of the structures in terms of load and displacement. In spite of its limitation for depicting certain non-linearity and failure modes as in continuum based modelling tool the number of users for the lumped plasticity modelling approach is widespread around the world.

Non-linear analysis involves non-linearity of material in the form of post peak response, geometric non-linearity in the form of hinges and inherent plastic behavior of the section and finally non-linear analysis as loading the structure beyond the elastic regime until failure. Push-over analysis is a simple non-linear static analysis approach involving a procedure of application of monotonically increasing lateral loading (also displacement) and recording the response in the form of shear force in the base of the structure. The plot of the force versus

*E-mail address: d6122300145@g.siit.tu.ac.th ISSN: 1791-2377 @ 2021 School of Science, IHU. All rights reserved. doi:10.25103/jestr.142.09 displacement provides the capacity or pushover curve, whose slopes depicts the stiffness of the structure. Researchers have been following the non-linear analysis provision as detailed in the ATC-40 [2] and FEMA 356 [3] as default parameters, available in program (SAP2000) which in some cases might not capture the real behavior of the structures. Hence, the current research studies possible variation of the response of the structures while adopting the user-defined and default non-linear property. Since, graphical interface of the analysis package SAP2000 [4] developed from Computer and Structures is user-friendly and versatile so this tool is adopted for linear and nonlinear seismic analysis of the structure. Contrarily, researcher might be fully dependent on the default modelling and analysis parameters and considerations of the tool and obtain results which might be far off from the real response of the existing structure. Obviously, the F.E tool includes properties based on various codal provision and guidelines which were verified based on large no of experiments and testing but response of all the structure cannot be fitted into the tool. Hence, average value is considered for developing the program which sometimes might lead to erroneous result. One of the major consideration is on the non-linear hinges, their location and behavior [5] , since the property is dependent on reinforcement detailing which is again different in countries. So, a clear understanding of the numerical model its capability and procedure should be done to perform the nonlinear analysis [6]. Several studies have been performed for non-linear modelling of the structures. Ladjinovi et al. (2012) [7] performed non-linear static analysis of the multistory frame structure from SAP2000 and Opensees. The wide modelling opportunity available in Opensees tool obviously predicted the better 
results but the results from the SAP2000 was also found satisfactory in predicting major non-linear points of forcedisplacement behavior of the structure.

Considering this fact, an attempt is done to predict the response of a frame previously tested by Vecchio and Emara, 1992 [8] using lumped plasticity models so that the researchers using these tool might be familiar with modelling strategies which should be adopted. Also, the same frame is remodeled with continuum mechanics based modeling tool LS-DYNA to depict the capability of modelling tool in representing the response and failure pattern of the tested frame with selection of suitable material model.

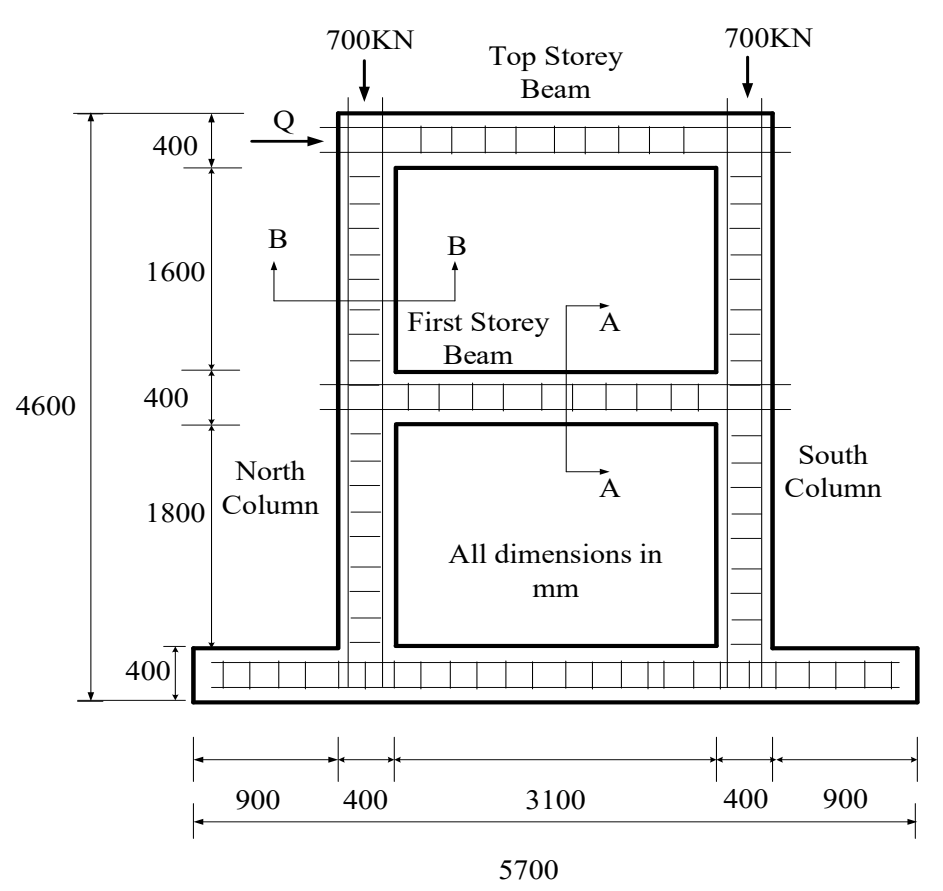

\section{Geometry, Material Property and Testing procedure of Specimen}

A one bay two storey 2D frame is taken as a verification model which was tested for evaluation of deformation in shear of RC Frame by Vecchio F.J and Emara M.B ,1992 [8]. The frame consists of all structural members of size $300 \mathrm{~mm}(12$ in.) by $400 \mathrm{~mm}$ (16 in.) and similar reinforcement details with $\mathrm{RC}$ base which was heavily reinforced.
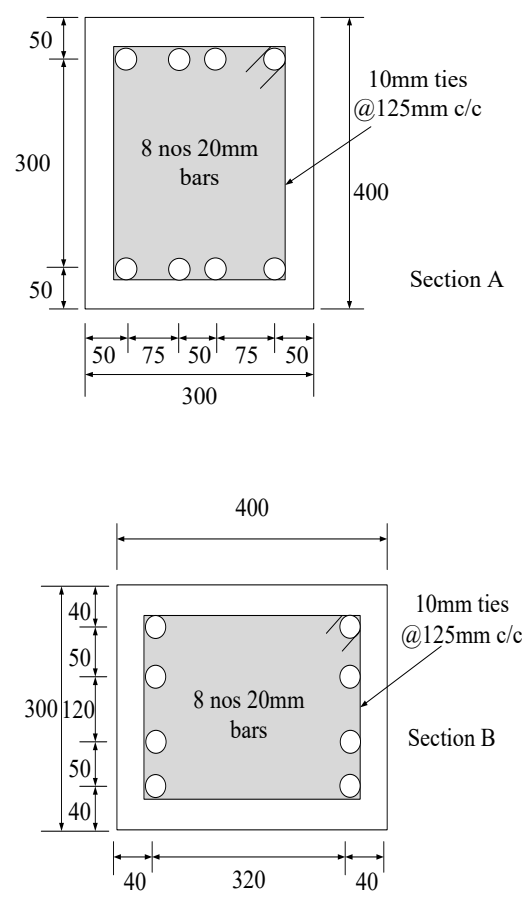

Fig. 1. Details of the frame for Testing [2]

The reinforcement consists of 4 no of $20 \mathrm{~mm}$ diameter deformed bars in top and bottom $\left(\rho_{s}=2.094 \%\right)$ and $10 \mathrm{~mm}$ transverse shear reinforcement with spacing of $125 \mathrm{~mm}$ $\left(\rho_{v}=0.419 \%\right)$ as in Fig. 1. Concrete of compressive strength $30 \mathrm{MPa}$ (4350psi) and stress strain curve as per the experiment [8] was adopted and properties of reinforcement were adopted as shown in Table 1.

Table 1. Material Parameters [8]

\begin{tabular}{l|l|l|l|l|l|l|r|}
\hline Bar No. & $\boldsymbol{D}_{\boldsymbol{b}}(\mathbf{m m})$ & $\boldsymbol{f}_{\boldsymbol{y}}(\mathbf{M P a})$ & $\boldsymbol{f}_{\boldsymbol{u}}(\mathbf{M P a})$ & $\boldsymbol{E}_{\boldsymbol{s}}(\mathbf{G P a})$ & $\boldsymbol{E}_{\boldsymbol{s} \boldsymbol{h}}(\mathbf{M P a})$ & $\boldsymbol{\varepsilon}_{\boldsymbol{s h}}$ & $\boldsymbol{\varepsilon}_{\boldsymbol{u}}$ \\
\hline 20 & 19.5 & 418 & 596 & 192.5 & 3100 & 0.0095 & 0.0669 \\
10 & 11.3 & 454 & 640 & 200 & 3100 & 0.0095 & 0.0695 \\
\hline
\end{tabular}

The frame was designed with a story height of 2000m (4 $\mathrm{ft}, 3 \mathrm{in})$ and span of $3500 \mathrm{~mm}(7 \mathrm{ft}, 5 \mathrm{in})$ with overall height of $4600 \mathrm{~mm}$ ( $9 \mathrm{ft}, 9 \mathrm{in})$. The testing performed was a quasi-static test to obtain the load deformation behavior and failure mode of the frame after application of monotonically increasing lateral displacement $(\mathrm{Q})$ as in Fig. 1. Displacement transducers (LVDTs) were placed at several locations to obtain the displacement of the frame under increasing loading. The test involved of applying the axial loading of $700 \mathrm{KN}$ (157 Kips) to each column throughout the test followed by monotonic increasing lateral loading. Loading was increased in a stoke controlled mode until the ultimate capacity of the frame was reached.

\section{Modelling Approach}

Inherent modelling capability and user defined modelling aspects in terms of section, material behavior, non-linearity modelling (hinges) is assessed and suitability of modelling criteria to depict the actual displacement capacity is studied for the lumped plasticity model. Also, the same frame is remodeled from the general purpose FE code LS-DYNA [9, 10] to understand the modelling capabilities and the results of SAP2000 and LS-DYNA solver is compared with the documented test results. Further, parametric study is performed for various widely accepted material models and a selection of the suitable material model which could depict the actual response of structure numerically was proposed for 
both modelling tool. The modelling consideration for both solvers are discussed in details in following paragraphs.

\subsection{Lumped Plasticity modelling}

A 2-dimensional model of the frame was created in SAP2000 in order to predict the response of tested frame numerically. Non-linear frame elements were adopted to model beams and columns with plastic hinges at the ends to depict nonlinearity. This method considers the lumped plasticity approach to model the structure and depicts the nonlinearity in the form of plastic hinges. The location of the plastic hinge zone is judged based on the possible predicted failure mechanism of the structure since addition of hinges in several locations will increase the computation cost [4].

\subsubsection{Material Property}

Generally, unconfined and confined material models are available in literatures to model the concrete material. Concrete specimen for low level of stress behaves as unconfined concrete with no role of the transverse rebar. With increasing stress beyond uniaxial strength the stirrups plays role, so they are usually named as passive confinement [11]. As the stress increases beyond the strength of specimen, internal progressive cracking occurs with increase in transverse strain. Now, stirrups starts to hold the concrete as a confining reaction preventing brittle damage of concrete. Hence, until concrete reaches maximum stress level, confinement by stirrups have less or no effect on the stressstrain curve. For high strain stress-strain curve of confined concrete depends on the volumetric ratio, strength of concrete and rebar, diameter and spacing of the stirrups etc. Usually, Stress-strain curve in compression of the concrete material has an parabolic ascending initial portion up to strain of 0.002 and then linearly descending portion $[12,13]$ which is sometimes even idealized as a straight line until the ultimate strain of 0.0035 [14].

Numerical modelling for non-linear analysis includes the non-linear material behavior of the members as moment curvature relationship and interaction curves $[15,16]$. Various material models for the modelling of the confined and unconfined concrete has been proposed [17, 18] including Mander et. al., 1988 [19], Kent and Park, (1971) [20], Cusson-Paultre, 1995 [21] and Hong-Hang Model [22].etc., and these four confined concrete material models are considered in present study (b)

Fig. 2).

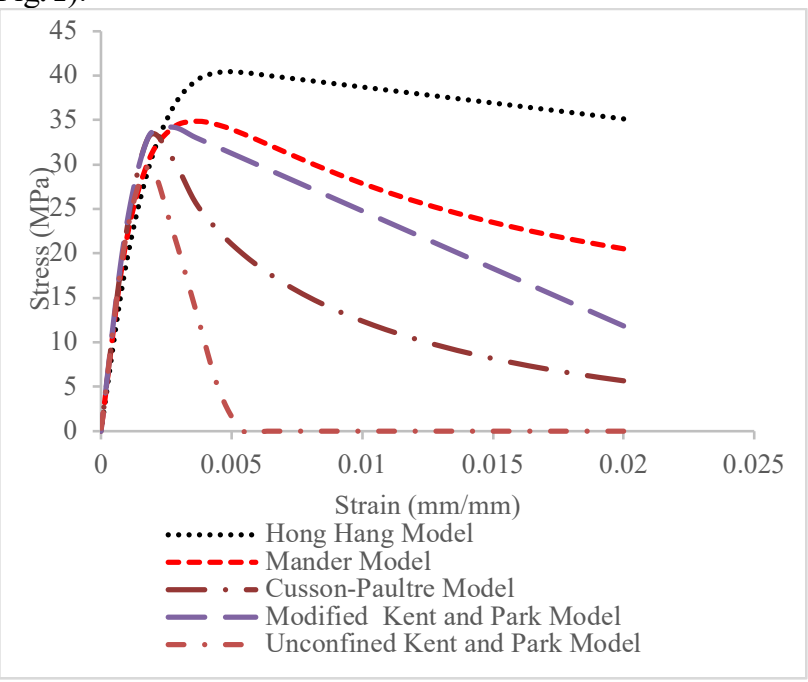

a)

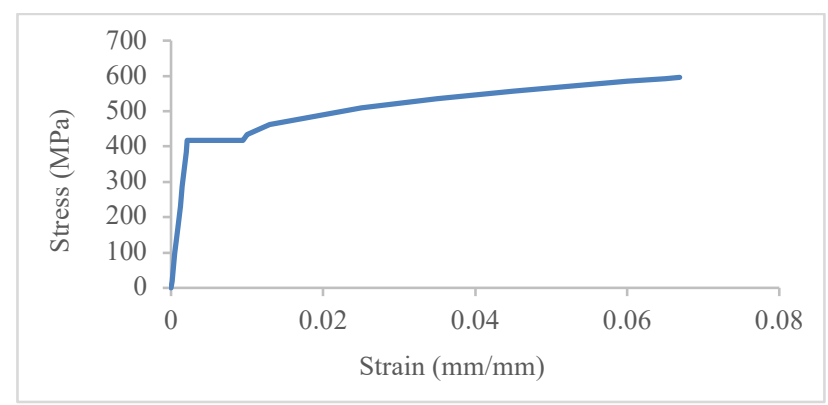

b)

Fig. 2. Stress-strain curve of (a) concrete and (b) rebar a) Concrete unconfined and confined material models and b) Reinforcement material model

Mander et. al, 1988 [19] formulated a theoretical concrete material model based on extensive testing of column under uniaxial compression and proposed a single equation to develop stress-strain curve of confined concrete based on $f_{c c}{ }^{\prime}$, $\varepsilon_{c c}$ and $E_{c}$ (ref [19]). These parameters depends on concrete unconfined cylinder strength and configuration of lateral ties (shear reinforcement). This model also includes unloading and reloading behavior for cyclic response of structure and has widespread popularity and used in CSI software as default material model.

Kent and Park, (1971) [20] suggested the stress-strain curve of the unconfined and confined concrete by using rectangular hoops. It can be observed that stress strain curve for confined concrete is exactly same as of unconfined until the peak ascending part ( $2^{\text {nd }}$ degree parabola) depicting no role of confining steel until this point and equal to cylinder strength, $f_{c}{ }^{\prime}$. During 1982, Kent and Park [23] further modified the stress strain model of concrete which depicts the enhancement of the strength of concrete with confinement effect. Inspite of adopting peak stress equal to cylinder strength, $f_{c}^{\prime}$ in case of Kent and Park, (1971) [20], slight modification for the stress was proposed for enhancement of strength of concrete due to confinement in modified Kent and Park Model [23] and equal to $k f_{c}{ }^{\prime}$. Also, it can be observed increment of the strength in the stress strain response of the material due to confinement since usually we measure the unconfined compressive strength of the concrete $\left(f_{c}^{\prime}\right)$. Cusson-Paultre, 1995 [21] examined the behavior of the highstrength confined concrete (HSC), since the previously developed formulations were only for normal strength concrete (NSC) which usually posseses ductile stress-strain response than HSC. Cusson-Paultre, 1995 obtained strong corelation among effective confinement index with strength and ductility of the confined concrete and further divided into 3 classes of low, medium and high confinement. In NSC confining pressure of confined concrete is usually predicted based on yield strength of lateral ties but for HSC the ties may or may not yield. Considering this fact Hong-Hang Model,2005 [22].proposed stress-strain model for high strength concrete. Hong-Hang Model,2005 observed that confinement effect doesnot increase with increasing yield strength of ties and performance of column having higher volumetric ratio with lower steel grade was better. The experiment procedure for the Hong-Hang Model,2005 was performed for high strength concrete (40 to $130 \mathrm{MPa}$ ), yield strength of tie (320 to $1300 \mathrm{MPa})$ and volumetric ratio of tie $(0.32$ to $1.92 \%)$.

Hence, four confined material models were adopted (2NSC and 2-HSC) for concrete modelling and in developing the moment curvature relationship of studied frame. The basis 
of selection is confined concrete material model is mentioned in Table 2.

Generally, the stress strain curve of reinforcement steel consists of elastic until $\varepsilon_{y}$, yield plateau (plastic), followed by curvilinear strain hardening until tensile stress reaches its maximum value and finally descending curve in strain softening until necking and fracture [24]. Readers are requested to see codal provision [14 - 25] for details. A simple rebar formulation as available in modelling tool was adopted for the rebar material modelling.

Table 2. Confinement Parameters on Stress-strain curve of concrete

\begin{tabular}{|c|c|c|c|c|c|c|c|}
\hline \multirow[b]{2}{*}{$\begin{array}{c}\text { Confinement } \\
\text { Model }\end{array}$} & \multirow[b]{2}{*}{ Parameters } & \multicolumn{6}{|c|}{ Parameters Affecting Confinement } \\
\hline & & $\begin{array}{c}\text { Dia of } \\
\text { Ties }\end{array}$ & $\begin{array}{l}\text { Spacing of } \\
\text { Ties }\end{array}$ & $\begin{array}{c}\text { Yield } \\
\text { strength of } \\
\text { Ties } \\
\end{array}$ & $\begin{array}{l}\text { Dia of } \\
\text { Main } \\
\text { Bars } \\
\end{array}$ & $\begin{array}{l}\text { Spacing of } \\
\text { Main Bars }\end{array}$ & $\begin{array}{l}\text { Yield strength } \\
\text { of Main Bars }\end{array}$ \\
\hline \multirow{3}{*}{$\begin{array}{l}\text { Hong Hang } \\
\text { Model }\end{array}$} & Peak Stress & $\sqrt{ }$ & $\sqrt{ }$ & $\sqrt{ }$ & $\sqrt{ }$ & $\sqrt{ }$ & $\sqrt{ }$ \\
\hline & Peak Strain & $\sqrt{ }$ & $\sqrt{ }$ & $\sqrt{ }$ & $\sqrt{ }$ & $\sqrt{ }$ & $\sqrt{ }$ \\
\hline & $\begin{array}{l}\text { Ultimate } \\
\text { Strain }\end{array}$ & $\sqrt{ }$ & $\sqrt{ }$ & $\sqrt{ }$ & $\sqrt{ }$ & $\sqrt{ }$ & $\sqrt{ }$ \\
\hline \multirow{3}{*}{ Mander Model } & Peak Stress & $\sqrt{ }$ & $\sqrt{ }$ & $\sqrt{ }$ & $\sqrt{ }$ & $\sqrt{ }$ & $\sqrt{ }$ \\
\hline & Peak Strain & $\sqrt{ }$ & $\sqrt{ }$ & $\sqrt{ }$ & $\sqrt{ }$ & $\sqrt{ }$ & $\sqrt{ }$ \\
\hline & $\begin{array}{l}\text { Ultimate } \\
\text { Strain }\end{array}$ & $\sqrt{ }$ & $\sqrt{ }$ & $\sqrt{ }$ & $\sqrt{ }$ & $\sqrt{ }$ & $\sqrt{ }$ \\
\hline \multirow{3}{*}{$\begin{array}{c}\text { Cusson Paultre } \\
\text { Model }\end{array}$} & Peak Stress & $\sqrt{ }$ & $\sqrt{ }$ & $\sqrt{ }$ & $\sqrt{ }$ & $\sqrt{ }$ & $\sqrt{ }$ \\
\hline & Peak Strain & $\sqrt{ }$ & $\sqrt{ }$ & $\sqrt{ }$ & $\sqrt{ }$ & $\sqrt{ }$ & $\sqrt{ }$ \\
\hline & $\begin{array}{l}\text { Ultimate } \\
\text { Strain }\end{array}$ & $\sqrt{ }$ & $\sqrt{ }$ & $\sqrt{ }$ & $\sqrt{ }$ & $\sqrt{ }$ & $\sqrt{ }$ \\
\hline \multirow{3}{*}{$\begin{array}{l}\text { Kent Park } \\
\text { Model }\end{array}$} & Peak Stress & $x$ & $x$ & $x$ & $\mathrm{x}$ & $\mathrm{x}$ & $x$ \\
\hline & Peak Strain & $\mathrm{x}$ & $\mathrm{x}$ & $\mathrm{x}$ & $\mathrm{x}$ & $\mathrm{x}$ & $x$ \\
\hline & $\begin{array}{c}\text { Ultimate } \\
\text { Strain }\end{array}$ & $\sqrt{ }$ & $\sqrt{ }$ & $\mathrm{x}$ & $\sqrt{ }$ & $\mathrm{x}$ & $\mathrm{x}$ \\
\hline
\end{tabular}

\subsubsection{Moment curvature}

For a particular reinforced concrete section as shown in Fig. 3, moment curvature relationship is developed with consideration of certain assumptions for the section under axial and flexure loading such as section remains plane even after bending, stress-strain curve of material is known and tension capacity is not considered of concrete. For the assumed linear strain profile with extreme compression $\varepsilon_{c m}$ and neutral axis depth, stress in the concrete can be obtained from stress-strain curve of material models. Also, strain in reinforcement can be obtained using similar triangle and corresponding stress from stress-strain curve of reinforcement steel. Hence, steel compressive or tensile force is calculated from product of the corresponding stress and area of reinforcing steel.

For concrete compressive force and its location from extreme compressive fiber, $\gamma k d$, equivalent rectangular stress block was used having width of mean stress of $\alpha f_{c}{ }^{\prime}$ and depth of $k d$ with considering the total compressive force and location being similar for actual and equivalent stress block. For any strain $\varepsilon_{c m}$ of extreme compression fibre mean stress factor $\alpha$, and centroid factor $\gamma$, was evaluated as:

Area under stress-strain curve $=\int_{0}^{\varepsilon_{c m}} f_{c} d \varepsilon_{c}=\alpha f_{c}{ }^{\prime} \varepsilon_{c m}$

$\alpha=\frac{\int_{0}^{\varepsilon_{c m}} f_{c} d \varepsilon_{c}}{f_{c}^{\prime} \varepsilon_{c m}}$

First moment of area was evaluated about origin of area and under stress-strain curve as

$\int_{0}^{\varepsilon_{c m}} f_{c} \varepsilon_{c} d \varepsilon_{c}=(1-\gamma) \varepsilon_{c m} \int_{0}^{\varepsilon_{c m}} f_{c} d \varepsilon_{c}$ $\gamma=1-\frac{\int_{0}^{\varepsilon_{c m}} \varepsilon_{c} f_{c} d \varepsilon_{c}}{\varepsilon_{c m} \int_{0}^{\varepsilon_{c m}} f_{c} d \varepsilon_{c}}$

Finally, compressive force in concrete is given by

$P=\alpha f_{c}^{\prime} b k d+\sum_{i=1}^{n} f_{s i} A_{s i}$

$M=\alpha f_{c}^{\prime} b k d\left(\frac{D}{2}-\gamma k d\right)+\sum_{i=1}^{n} f_{s i} A_{s i}\left(\frac{D}{2}-d_{i}\right)$

Curvature, $\varphi=\frac{\varepsilon_{c m}}{k d}$

Where, $\varepsilon_{c m}$ is the strain of extreme compression fiber, $\mathrm{k}$ is the coefficient for neutral axis and $d$ is the effective depth of the section

Using the above theoretical formulations moment capacity and corresponding curvature was evaluated based on variation of strain on the extreme compression fiber. Moment curvature relationship was developed for various confined material models by Microsoft Excel (Visual Basic Application) and was defined as user defined values in the modelling tool. The moment curvature relationship for beam for various confined material models with no axial load (Axial $\mathrm{Load}=0$ ) is depicted in Fig. 3. The moment curvature relationship of column for various confined material models with axial load (Axial $\mathrm{Load}=700 \mathrm{KN}$, compression) is depicted in Fig. 3. It can be observed that the Moment curvature response after adopting confined material model of Cusson Paultre seems to have slightly different in comparison to other considered material models. It is because of the stress-strain curve developed for this material model as seen in b)

Fig. 2. 

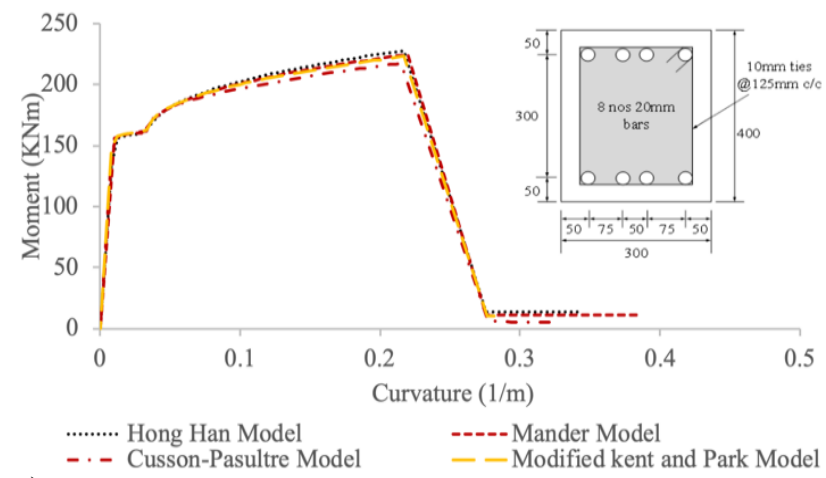

a)

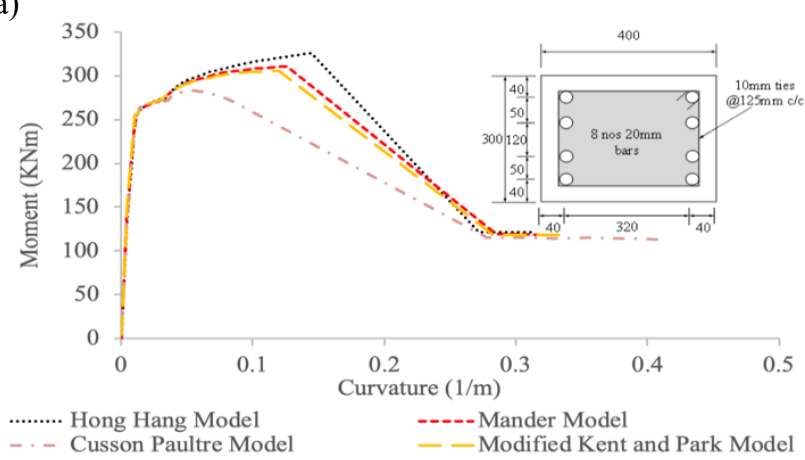

b)

Fig. 3. Moment curvature relationship for beam and column a)Beam and b) Column Section

For column P-M3 diagram was also generated based on the different confined concrete material model based on strain compatibility method as shown in Fig. 4.

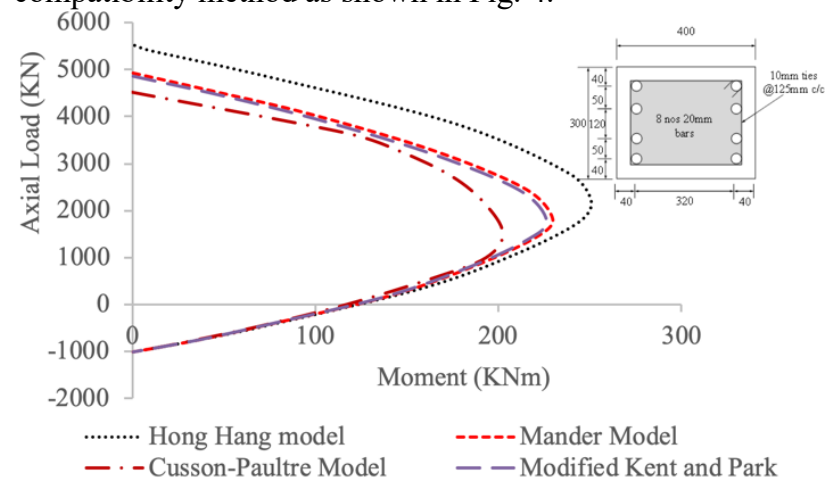

Fig. 4. Load moment relationship for column

The actual section is modelled by section designer feature available within the modelling tool SAP2000 which then automatically calculates hinge properties of the section designed (auto hinge) and considers P-M3 hinge for column and M3 hinge for beams. In the present study an attempt is done to provide user-defined hinge based on the momentcurvature analysis of the structural elements. Various confined material models as discussed above are adopted for moment curvature analysis. For effective consideration of crack section the value of moment of inertia for the non-linear analysis was estimated to be $0.35 I_{g}$ and $0.70 I_{g}$ for beam and column respectively [12]. Concrete is well-known for its brittle nature but still softening beyond the plastic phase is observed so hinge length is usually adopted for analysis of structures with strain softening behavior. Plastic hinge zone is the region of localized plastic deformation after the member yields. Hinge length is an important parameter showing the length of confinement to enhance the seismic performance in terms of ductility allowing survival of the structure for extreme loading events like earthquake [26]. P Mendis, 2001 [27] formulated and re-examined the previously developed formulations for the hinge length and observed that softening effect is more significant for hinge length with smaller value. The author conclude that hinge length is critical parameter in depicting the non-linear behavior of the structure and is tedious to evaluate theoretically so experimental results should be followed while estimating the length of hinge. ATC-40 [2] defines the evaluation criteria for plastic rotation based on the plastic curvature as : $\theta_{p}=\left(\phi_{u}-\phi_{y}\right) L_{p}$ where, plastic length $\left(L_{p}\right)$ is related with yield $\left(\phi_{y}\right)$ and ultimate curvature $\left(\phi_{u}\right)$.which are based on the actual behavior of cross-section. Since the modelling tool requires input of moment-rotation rather than moment-curvature and also only few salient points(5number) can only be included in the tool, the above formulation of plastic hinge length is usually used to evaluate the ultimate rotation from ultimate curvature. Readers are requested to go through the various literatures not only limited to [26 - 30] for obtaining length of hinge analytically. ATC-40 [2] calculated the plastic hinge length based on cross-section depth as $0.5 \mathrm{~h}$. For estimation of the plastic hinge length a well-known formulation, $l_{p}=0.081+$ $0.022 d_{b} f_{y}$ suggested by Pauley and Priestley (1992) [31] considering the rebar contribution can also be used.

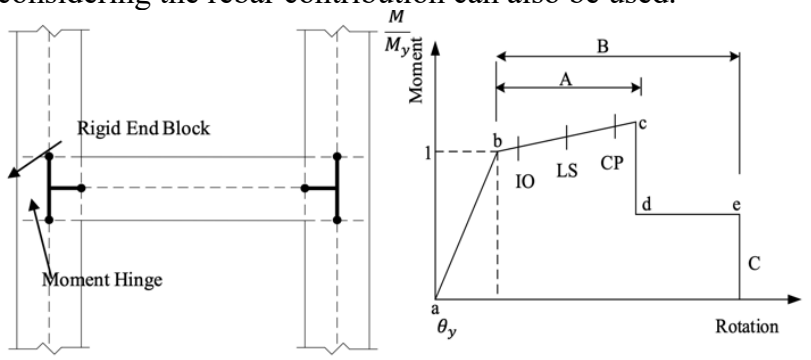

Fig. 5. (a) Location of Hinge and (b) Moment Rotation relationship

For current study the plastic hinge length equal to section depth is considered [32].

Fig. 5 shows normalized moment versus rotation relationship showing $\frac{M}{M_{y}}=1$ as yield value and strain hardening leading to ultimate moment followed by failure. The numerical values of the parameters $\mathrm{A}, \mathrm{B}$ and $\mathrm{C}$ can be obtained from the guidelines [3] and experimental results.

Table 3. Hinge Properties and acceptance criteria adopted for user defined section

\begin{tabular}{|c|c|c|c|c|}
\hline Point & Moment/SF & Rotation/SF & Immediate Occupancy (IO) & $\begin{array}{ll}10 & \% \\
\frac{\theta_{p}}{\theta_{y}} & \\
\end{array}$ \\
\hline $\mathrm{a}$ & 0 & 0 & Life safety (LS) & $\begin{array}{ll}60 & \% \\
\frac{\theta_{p}}{\theta_{y}} & \\
\end{array}$ \\
\hline
\end{tabular}




\begin{tabular}{|c|c|c|}
\hline $\mathrm{b}$ & 1 & 0 \\
$\mathrm{c}$ & $\frac{M_{u}}{M_{y}}$ & $\frac{\theta_{p}}{\theta_{y}}$ \\
$\mathrm{~d}$ & $0.2 \frac{M_{u}}{M_{y}}$ & $\frac{\theta_{p}}{\theta_{y}}$ \\
$\mathrm{e}$ & $0.2 \frac{M_{u}}{M_{y}}$ & $1.5 \frac{\theta_{p}}{\theta_{y}}$ \\
\hline
\end{tabular}

The user defined moment rotation relationship is developed from the ultimate rotational capacity of the

\begin{tabular}{|lll}
\hline Collapse Prevention (CP) & $90 \%$ \\
& $\frac{\theta_{p}}{\theta_{y}}$ & \\
\hline
\end{tabular}

structural elements with hinge properties and acceptance criteria as shown in

Table 3 [33].

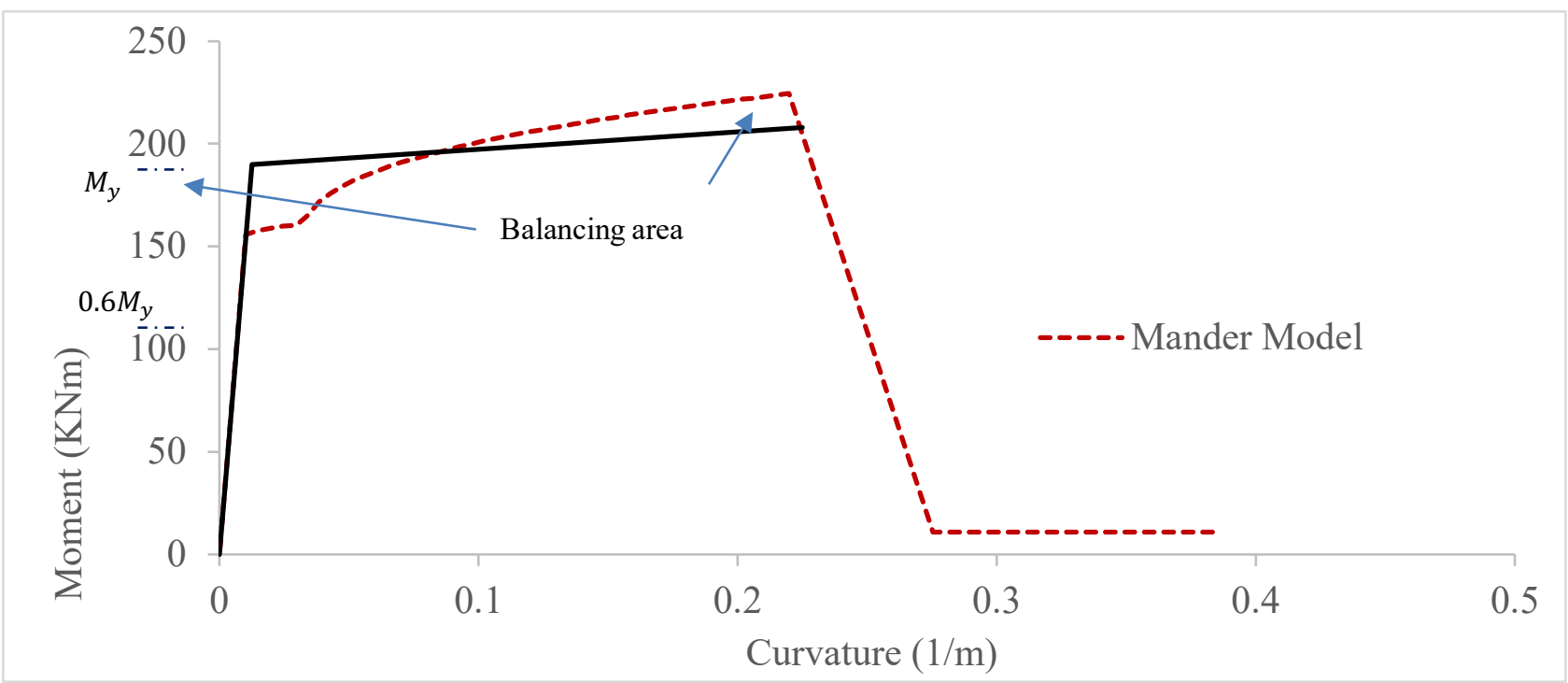

Fig. 6. Procedure for bi-linearization of actual moment curvature curve

The actual moment curvature is then converted to bilinear graph including salient points since few data can only be provided as input in the modelling tool.

The procedure of obtaining bilinear curve includes trial and error approach as making equal area below and above the actual curve with initial line passing through $60 \%$ of idealized yield moment curve as shown in Fig. 6. Calculation of the base shear and its distribution along the building can be assumed as linear [34], quadratic [35] and also with higher order so selection of suitable pattern of loading is of paramount important. Mwafy, 2001 [36] concluded that uniform pattern of load distribution typically induced higher resistance to seismic load with respect to inverse triangular and quadratic pattern because of less overturning moment. Readers are requested to go through [36, 37], for explanation of the Fig. 7. .

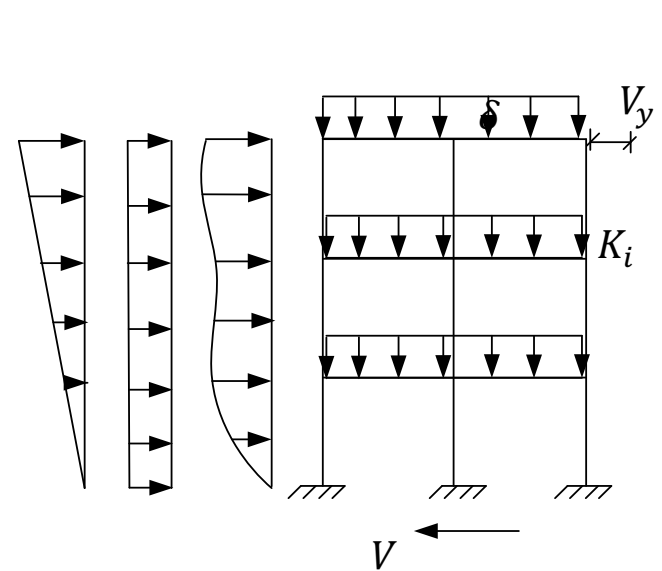

(a)

(b)

(c)

(d)

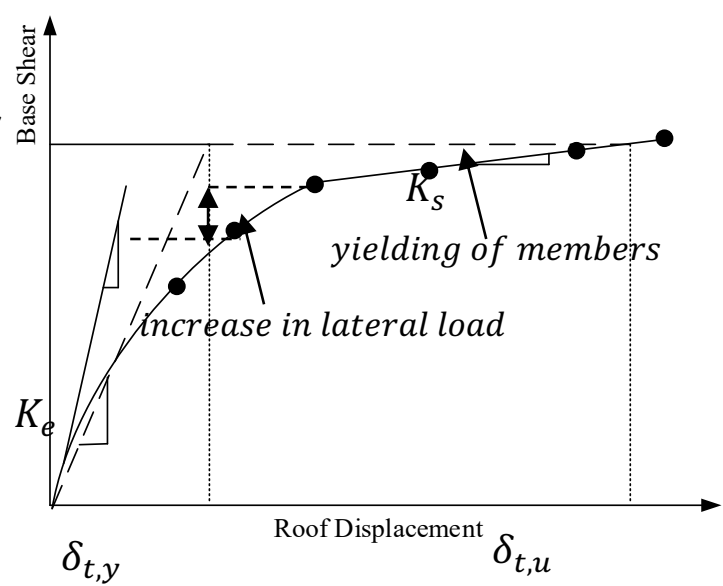

(e)

Fig. 7. Illustration of Non-linear static analysis 
Performance of the structure is the evaluation of the capacity and demand of the structures and their point of intersection on the capacity curve. Generally, spectrum curve is provided as a demand from codal provisions [34,35] and the capacity curve is converted to acceleration displacement response spectra format [2] commonly known as Capacity Spectrum method. Leslie, 2013 [38] explained that the procedure described in ATC-40 [2] can be adapted for the seismic parameters of IS: 1893-2002 [35].

\subsection{Continuum based modelling}

A general purpose high fidelity numerical tool LS-DYNA was adopted to simulate the response of the frame subjected to lateral displacement. LS-DYNA, finite element (FE program) is well-known for its availability of several contact algorithms, broad spectrum of material models, solvers (implicit, explicit, thermal, ALE, ICFD), accuracy in responses of simulation, etc. and is preferred among other similar FEA code available. A detailed 3 D finite Element modelling is performed in a numerical tool LS- DYNA to observe the damage pattern and load displacement behavior of the previously tested 2D frame. Modelling the frame i.e., beams and columns structural members, were modelled with solid brick elements (eight nodes hexahedron) while rebar were modeled as beam elements, and were constrained in the concrete perfectly showing no slippage of the rebar and concrete. A special feature of the solver can also be introduced in the study of behavior of frame i.e., slippage of the rebar and concrete. Usually, the Constrained beam in solid (CBIS) uses the perfect (no slippage) interaction of rebar and concrete represented by beam and solid element respectively. Slippage can be evoked by setting AXFOR=-Function ID and defining the bond slip function as per CEB formulations [13], [39] or any other formulations [40]. After performing the mesh convergence study, a uniform mesh size of $45 \mathrm{~mm}$ was adopted for both solid and beam elements (Fig. 8). Numerical convergence study showed that further refining the mesh showed a little variation in the response of the frame. Behavior of Plain concrete when subjected to multiaxial compression can be represented by the constitutive material model. In current work, three material model are adopted to predict and obtain the reliable behavior of concrete under monotonously increasing lateral loading.

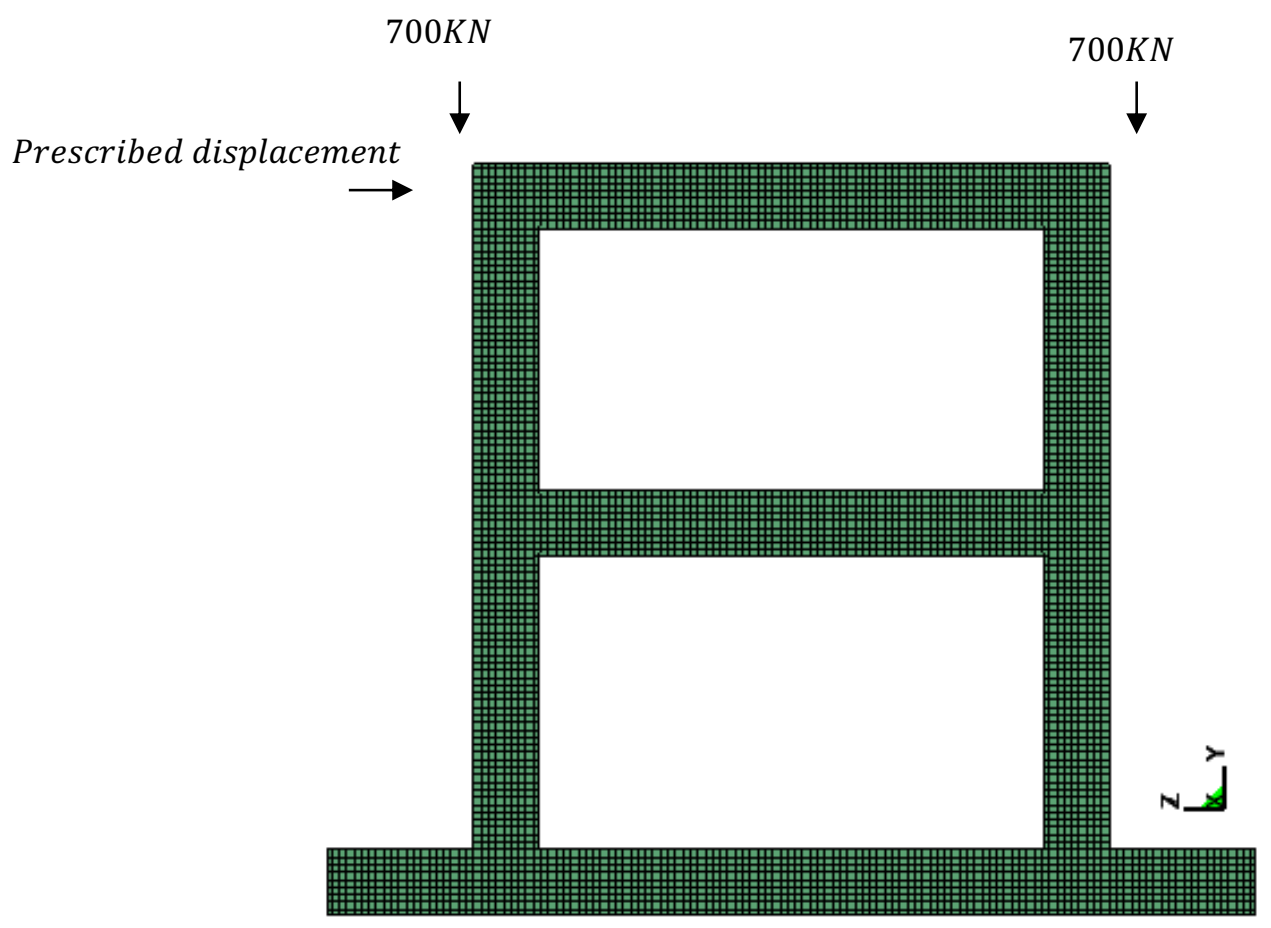

Fig. 8. Finite Element Meshing

A wide database of material properties is available inbuilt with LS-DYNA for various loading and material behavior for various levels of strain. Karagozian and Case (K \& C) also known as Material Type 72R3 (Release III) is a linear concrete damage model consisting of three independent failure surface namely maximum, yield and residual which changes according to the pressure. This model was originally developed for analyzing the structures subjected to blast loading by Javier Marvar [41] which was initially based on the Pseudo-tensor model and implemented in DYNA3D. Since the input of the same model in LS-DYNA (TYPE 72) was tedious so an improved new material model was formulated as K \& C (MAT 073) with automatically generation of parameters based on the unconfined compressive strength and density of the concrete. Detailed explanation on this material model can be obtained on literatures [42 - 44] with calibration of the material models $[45,46]$. For current study, automatic parameter generation capability is adopted with additional input of softening parameters $b_{1}, b_{2}$, and $b_{3}$ representing mesh sensitivity [47] $\left(b_{1}=0.34 h+0.79\right)$, factor for plastic straining which depends on aggregate size $\left(b_{2}\right)$ [48] and for tri-axial tension damage coefficient $\left(b_{3}\right)$ ranging from 1.1 and 1.6 [43].

For modelling in LS-DYNA the material model Continuous surface cap model (CSCM) was also adopted for concrete because of the simple formulation and previous validation study performed.[49 - 53]. Another, special feature of CSCM is the auto-generation of the material parameters 
based on uniaxial compressive strength and mass density of the concrete for normal strength concrete [44]. CSCM also has the inbuilt erosion option which deletes the failed material based on maximum principle strain and damage variable.

For modelling reinforcement, material model which is suitable for the simulation of both isotropic and kinematic hardening plasticity namely Plastic Kinematic Model (MAT_003) was adopted. [44]. This model is suitable to Hughes-Liu beam element and requires only input of properties like Young's and tangent modulus, Poisson's ratio, yield stress and hardening parameter $(\beta)$ of the steel. Value of beta $=1$ and 0 results in the material model with behavior of elastic plastic with kinematic and isotropic hardening respectively.

The bottom nodes of the heavily reinforced base were assigned as the support for boundary condition with two vertical loadings on the top of the column in second floor as shown in Fig. 1 i.e., arrangement of original testing. Since quasi static testing was performed in laboratory so to simulate this behavior implicit solver was utilized. The vertical load of intensity $700 \mathrm{KN}$ was applied uniformly as a pressure to the column cross-section. The load was applied as a ramped load for $1.99 \mathrm{sec}$ (peak load attained) and held constant followed by monotonically increasing lateral displacement as prescribed nodal displacement.

\section{Results and Discussion}

The model is analyzed for non-linear response and the output is plotted as the force displacement curve as shown in Fig. 9. From the plot it can be observed that the experimental results have variation i.e., underestimated from the adoption of defaults modelling parameters of the modelling tool. However, the user-defined parameters could depict the performance in better way in terms of load displacement behavior.

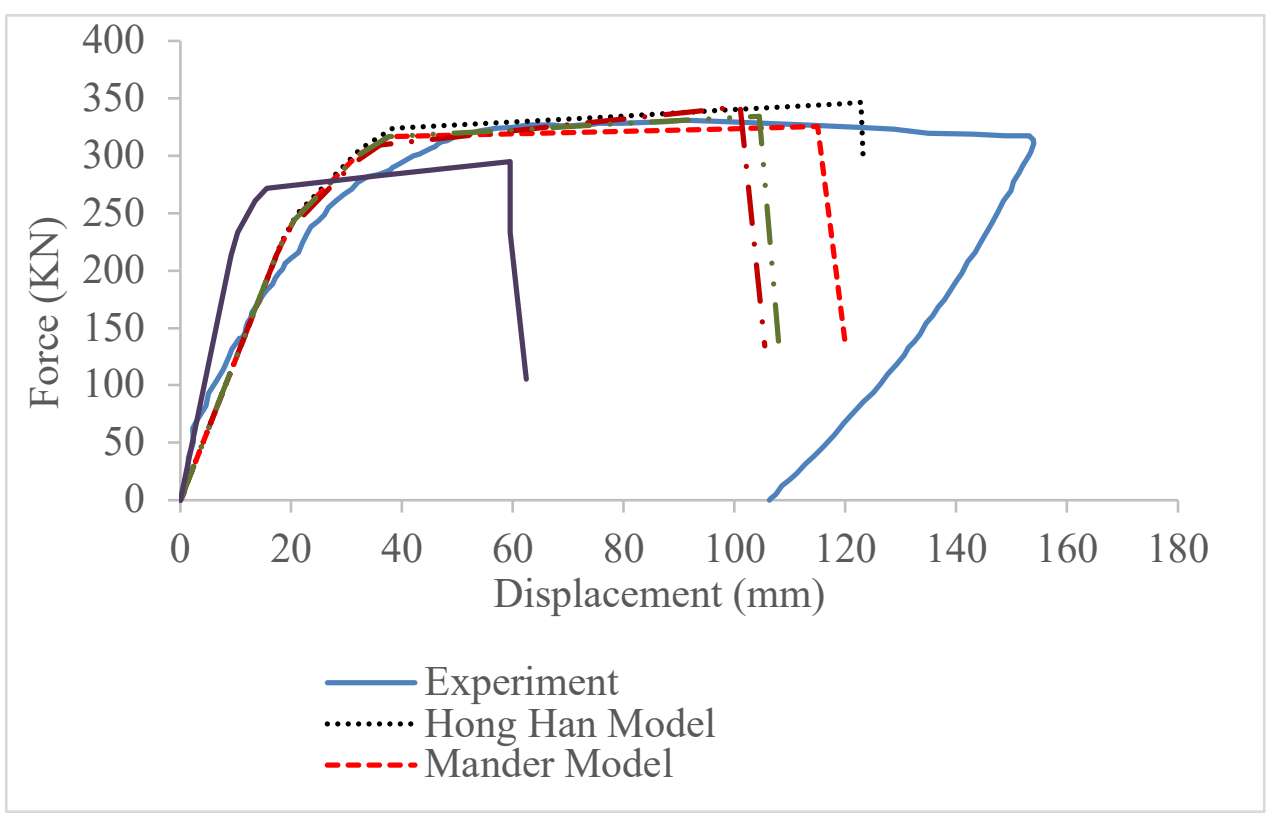

Fig. 9. Force displacement plot from lumped plasticity based modelling

A good estimation of the ultimate load could be observed with slight underestimation of ultimate displacement. Initially SAP2000 default (auto) hinge follows the similar force displacement behavior as obtained from experimental procedure until crack occurs on the section. While adoption of reduced stiffness as mentioned in codal provisions [12] in user defined section the response is underestimated until the cracking occurs on the section. After the progression of crack, SAP2000 default (auto) option could not depict the actual load displacement response according to experiment and wide variation was observed while the user-defined modelling approach could capture the salient load displacement points. Also, the response of all the confined concrete material models were observed to be somehow similar since the governing principle in developing these material model relies on configuration of lateral and longitudinal confinement parameters. Hence, it is recommended to adopt user-defined modelling approach rather than following default hinge with concrete confinement model for realistic modelling.

As shown in Fig. 10 the degradation of the rigidity after the peak load of $332 \mathrm{KN}$ with good ductility was observed until the $150 \mathrm{~mm}$ displacement according to experimental results. The initiation of damage in the frame was observed as flexural cracks on the north bottom and south top column which resulted in decrease in stiffness of the frame. On further loading web-shear cracks seemed to propagate in the first storey beams followed by yielding of longitudinal reinforcement. Due to the yielding of tensile and compressive reinforcement and crushing of concrete yielding at the base of both column, and hinging phenomena was observed resulting in flexure dominate failure mode of the specimen which was similar to the tested specimen.

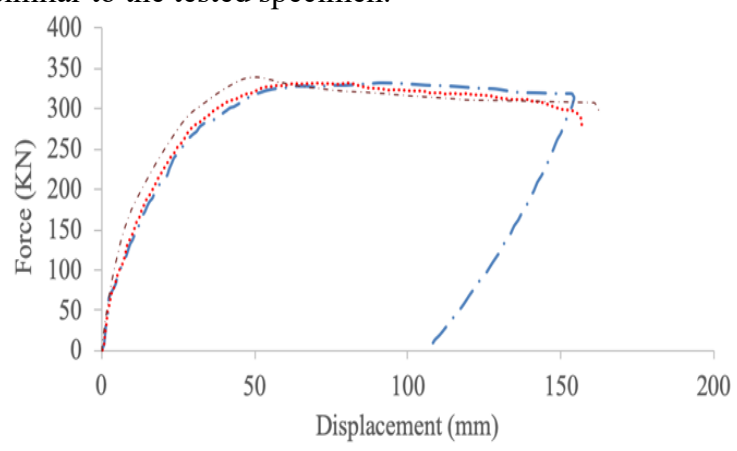

-.-Experiment ……... LS-DYNA (CSCM) ….... LS-DYNA (K and C)

Fig. 10. Comparison of Force Displacement relation from continuum based modelling 
The 3D modelling of the frame and its loading with boundary conditions as per experimental procedure in LSDYNA depicted good convergence with experimental results. The force displacement curve seems to predict the yield and ultimate loading with higher accuracy. Also, the damage pattern is compared with available failure pattern according to experiment. The lumped plasticity model can only show the non-linearity in the form of plastic hinge by changing the color depicting the level of damage as IO, LS and CP. While LS-DYNA can also exhibit the failure pattern as maximum of ductile and brittle damage by adopting NPLOT $=1$ in the card of material model of CSCM. The fringes of the effective plastic strain at ultimate loading level is shown in c Fig 11. Also, as per experimental results similar failure pattern was observed as vertical flexural cracks in the north top joint and formation of plastic hinge with spalling of concrete in the bottom south joint in numerical study while adopting the LSDYNA numerical tool. The modelling tool was able to capture the load-displacement behavior, and to a large extent, the failure modes of the frame observed in the experiment.

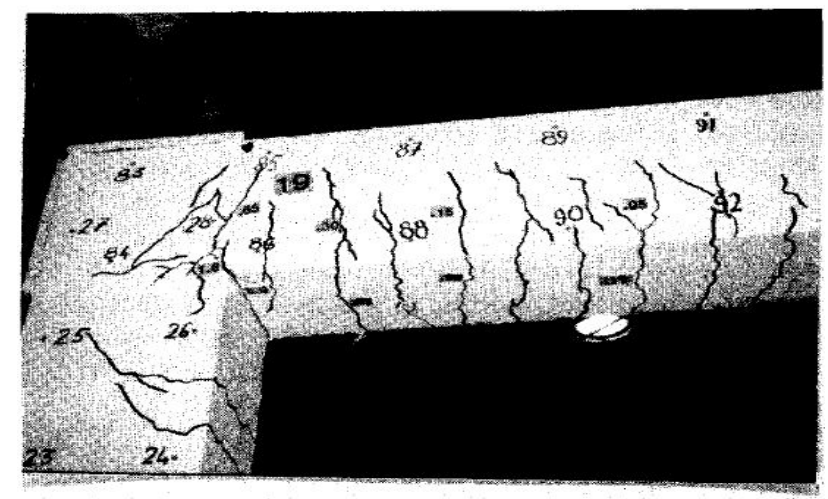

a)

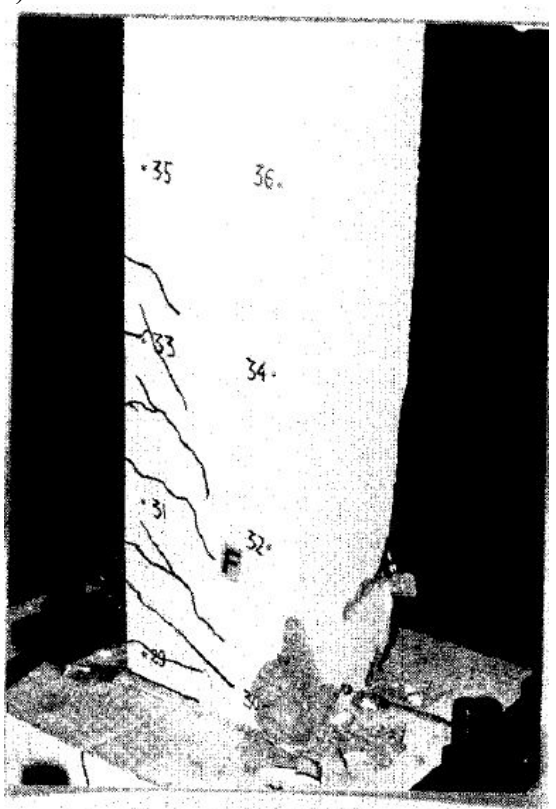

b)
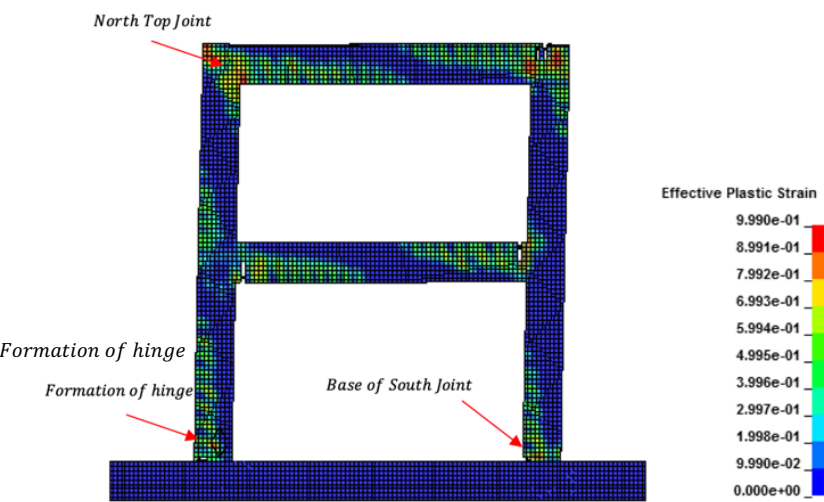

c)

Fig. 11. a)North - Top Joint, b) Base of South Joint and c) Comparison of Damage pattern

Based on the observed response of the frame CSCM material model is recommended to be used not only because of its minimum input required but also it could capture the failure pattern with inbuilt erosion algorithm and softening behavior.

The results as predicted by use of CSCM and KCC material model have variation although the theoretical formulation of CSCM and KCC are somehow similar. Both of them can be represented by three surfaces namely yield, limit and residual in generalized form ([52 - 53]), which represents the degradation of the response due to softening by gradual shifting of limit surface towards residual surface.

The three surfaces of KCC model are defined as:

$$
\begin{array}{ll}
\text { Initial Yield Surface, } & Y y=a_{0 y}+\frac{p}{a_{1 y}+a_{2 y} p} \\
\text { Limit Surface, } & Y m=a_{0 m}+\frac{p}{a_{1 m}+a_{2 m} p} \\
\text { Residual Surface, } & Y r=a_{0 r}+\frac{p}{a_{1 f}+a_{2 f} p}
\end{array}
$$

In KCC model the initial user input parameters for limit, yield and residual surfaces are represented by a-parameters $\left(\mathrm{a}_{0 \mathrm{y}}, \mathrm{a}_{\mathrm{ly}}\right.$, $a_{1 y}, a_{0 m}, a_{1 m}, a_{2 m}, a_{0 r}, a_{1 f}$ and $\left.a_{2 f}\right)$ and $p=I_{1} / 3$ is the pressure.

The failure surface is interpolated between limit $\left(\mathrm{Y}_{\mathrm{m}}\right)$ or residual $\left(\mathrm{Y}_{\mathrm{r}}\right)$ depending on following conditions:

$$
\begin{aligned}
& \mathrm{f}\left(\mathrm{I}_{1}, \mathrm{~J}_{2}, \mathrm{~J}_{3}\right)= \\
& \left\{\begin{array}{l}
r\left(J_{3}\right)\left[\mathrm{\eta}(\lambda)\left(Y_{m}(p)-Y_{y}(p)\right)+Y_{y}(p)\right] \text { for } \lambda \leq \lambda_{m} \\
r\left(J_{3}\right)\left[\eta(\lambda)\left(Y_{m}(p)-Y_{r}(p)\right)+Y_{r}(p)\right] \text { for } \lambda>\lambda_{m}
\end{array}\right.
\end{aligned}
$$

where $\lambda$ accounts for the internal damage (modified effective plastic strain) and is expressed as in Eq. 9 and $r\left(\mathrm{~J}_{3}\right)$ is function of third deviatoric stress. For incorporation of shear damage accumulation, rate effect is also considered as dynamic increasing factor based on CEB -FIB Model code 90 for higher load rates by a factor $r_{f}$, (strain rate enhancement factor).

$\lambda=\mathrm{h} \sqrt{\frac{2}{3} \varepsilon_{i j}^{p} \varepsilon_{i j}^{p}}$

where $\varepsilon_{i j}{ }^{p}$ is the strain tensor.

Various parameters like softening (h), tensile strength of concrete $\left(f_{t}\right)$, pressure (p) and DIF, are represented as: 
$\mathrm{h}=\left\{\begin{array}{l}\frac{1}{r_{f}\left(1+\frac{p}{r_{f} f_{t}}\right)^{b_{1}}} \text { for compression }(p \geq 0) \\ \frac{1}{r_{f}\left(1+\frac{p}{r_{f} f_{t}}\right)^{b_{2}}} \text { for tension }(p<0)\end{array}\right.$,

Where the parameters $b_{1}$ and $b_{2}$ accounts for softening behavior of material in compression and tension, respectively and $r_{f}$ is a experimental rate enhancement factor. Although, KCC model have inherent softening parameters while the variation of the experiment and simulation still exists. The main reason might be due to the use of auto parameter generation feature available based on input of unconfined compressive strength and density of concrete. The strain rate effects curve (LCRATE in keyword Card 3) which holds significant importance in softening and damage accumulation is not generated resulting in slightly higher force prediction.

However, CSCM concrete model is a cap model with a smooth or continuous intersection between the failure surface and hardening cap. In this concrete material model, the concrete strength is mainly governed by tensile shear surface, cap surface and the combination of tensile shear surface and cap surface depending on the pressure-regime. The yield surface of this model can be expressed as three invariants as follows $[9,10]$ :

$\mathrm{Y}\left(\mathrm{I}_{1}, \mathrm{~J}_{2}, \mathrm{~J}_{3}\right)=\mathrm{J}_{2}-\mathrm{R}\left(\mathrm{J}_{3}\right)^{2} \mathrm{f}_{\mathrm{f}}^{2}\left(\mathrm{I}_{1}\right) \mathrm{f}_{\mathrm{c}}\left(\mathrm{I}_{1}, \mathrm{k}\right)$

Where, $f_{f}\left(I_{1}\right)$ is the shear failure surface, $R\left(J_{3}\right)$ represents the Rubin three-invariant reduction factor, and $\mathrm{f}_{\mathrm{c}}\left(\mathrm{I}_{1}, \mathrm{k}\right)$ represents hardening cap with $\mathrm{k}$ as cap hardening parameter, which is defined as follows:

Shear Failure Surface, $\mathrm{f}_{\mathrm{f}}\left(\mathrm{I}_{1}\right)=\alpha-\lambda(\exp )^{-\beta \mathrm{I}_{1}}-\theta \mathrm{I}_{1}$

Cap Hardening Surface, $\mathrm{f}_{\mathrm{c}}\left(\mathrm{I}_{1}, \mathrm{k}\right)=$

$1-\frac{\left(\mathrm{I}_{1}-\mathrm{L}(\mathrm{k})\right)^{2}}{(\mathrm{X}(\mathrm{k})-\mathrm{L}(\mathrm{k}))^{2}} \quad$ for $\mathrm{I}_{1} \geq \mathrm{L}(\mathrm{k})=1$ otherwise

$L(K)= \begin{cases}K & \text { for } \mathrm{k} \geq \mathrm{K}_{0} \\ \mathrm{~K}_{0} & \text { otherwise }\end{cases}$

$X(k)=L(k)+R f_{f}\left(I_{1}\right)$

where the parameters $\alpha, \beta, \theta$, and $\lambda$ are based on triaxial compression tests on plain concrete and then, the parameters are adjusted for compaction and damage(.[52 - 53]). The shear failure surface and cap hardening surface intersects at $\mathrm{I}_{1}=$ $\mathrm{L}(\mathrm{k})$. Moreover, Cap hardening surface (Eq. 13) is represented by an ellipse when $\mathrm{I}_{1} \geq \mathrm{L}(\mathrm{k})$ and $\mathrm{R}$ is the cap ellipticity. Eq. 15 governs the location of cap whose motion determines the shape of pressure volumetric strain curve. Moreover, increased value of $\mathrm{X}(\mathrm{K})$ and $\mathrm{K}$ indicates expansion of cap and vice-versa. And following hardening rule is implemented to control the motion of cap:

Plastic volumetric strain,

$\varepsilon_{\mathrm{v}}^{\mathrm{p}}=\mathrm{W}\left[1-\exp ^{\left(-\mathrm{D}_{1}\left(\mathrm{X}-\mathrm{X}_{0}\right)-\mathrm{D}_{2}\left(\mathrm{X}-\mathrm{X}_{0}\right)^{2}\right.}\right]$

where $\mathrm{W}$ is the maximum value of volumetric strain, $\mathrm{X}_{0}$ represents the initial location of the cap (when $\mathrm{k}=\mathrm{k}_{0}$ ). $\mathrm{D}_{1}$ and $\mathrm{D}_{2}$ are the model input parameters.

As compared to KCC model, CSCM concrete model have the inbuilt parameters to depict the dynamic increasing factor during tension and compression which is captured from the softening parameters A, B, C and D [9, 10] during brittle and ductile damage and is calculated as

Brittle damage,

$$
\mathrm{d}\left(\tau_{\mathrm{b}}\right)=\frac{0.999}{\mathrm{D}}\left[\frac{1+\mathrm{D}}{1+\operatorname{Dexp}^{-\mathrm{C}\left(\tau_{\mathrm{b}}-\mathrm{r}_{0} \mathrm{~b}\right)}}-1\right](17)
$$

Ductile damage,

$$
\mathrm{d}\left(\tau_{\mathrm{d}}\right)=\frac{\mathrm{dmax}}{\mathrm{B}}\left[\frac{1+\mathrm{B}}{1+\exp ^{-\mathrm{A}\left(\tau_{\mathrm{b}^{-}} \mathrm{r}_{0}\right)}}-1\right]
$$

where,

Brittle damage accumulation, $\tau_{\mathrm{b}}=\sqrt{\mathrm{E} \varepsilon^{2} \text { max }}$

Ductile damage accumulation, $\tau_{\mathrm{d}}=\sqrt{\frac{1}{2} \sigma_{\mathrm{ij}} \varepsilon_{\mathrm{ij}}}$

where $\sigma_{\mathrm{ij}}$ and $\varepsilon_{\mathrm{ij}}$ are the stress and strain components, respectively.

Viscoplastic damage threshold, $r_{0}=\left(1+\frac{\text { Eśn }}{r^{s} \sqrt{E}}\right) r^{s}$

Where, $r_{0} d$ and $r_{0} b$ are the threshold ductile and brittle damage parameters (Eq. 17 and Eq. 18); the damage initiates only when $\tau_{b}$ and $\tau_{d}$ exceed respective thresholds. $r^{s}$ and $r_{0}$ represent damage threshold before and after application of viscoplasticity.

Hence, due to the inbuilt parameters to capture softening behavior the CSCM model could depict similar peak load and respective displacement with good accuracy for the studied frame. In case of KCC, the theoretical background is almost similar with CSCM with potential for a simulation of softening behavior of concrete but lacks automatically generated DIF input resulting in slightly variation of the response of the structure. However, it is utmost noted that the present study is relied on the response evaluation of the frame with auto-generation parameters of the material model with minimum input such as density and compressive strength for the material models. Detailed fitting of the material card is not performed because of unavailable data from the real testing and also since it is not the scope of this research.

\section{Conclusion}

This paper evaluates the seismic performance of a 2D frame tested previously by two approaches of modelling. After modelling the frame according to Classical lumped plasticity models in SAP2000 with default modelling approaches the response was observed to be under estimated. However, the accuracy was better when the defaults properties of material model, geometric and overall non-linearity in forms of hinges was made user defined as per the real section designer. On the other hand, the continuum mechanics based modelling approach using LS-DYNA solver could capture the response of the frame under lateral load with significant accuracy. The obtained results can be enumerated as below:

- The actual performance of the structure was obtained and compared from widely adopted numerical tool which will finally help designers to predict the behavior of the structures subjected to lateral loading.

- The capacity curve for default hinge model might be reasonable for modern code complaint structures. In several country construction practice might not conform with requirements of modern code detailing so special 
care should be performed while using default hinge to depict non-linearity of the structure.

- $\quad$ CSCM material model could depict the softening behavior of the concrete and consequently could predict reliable load-displacement and failure pattern with higher accuracy. Also, based on the theoretical background of the material model, CSCM (MAT 159) is recommended to use for evaluation of the structure under lateral loading.

- With the use of user-defined input parameters to depict non-linearity of the system, the response prediction of the studied frame was observed to be significantly improved for both modelling approaches. Hence, it is encouraged to explore the user defined parameters and to avoid the misuse of default non-linear modelling procedure and be aware of what the program is using to reflect the non-linear behavior.

This is an Open Access article distributed under the terms of the Creative Commons Attribution License.

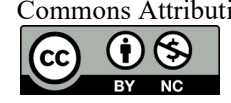

\section{References}

1. Lopez-Almansa F, Alfarah B, Oller S. Numerical simulation of RC frame testing with damaged plasticity model. Comparison with simplified models. InSecond European conference on Earthquake Engineering and Seismology, Istanbul, Turkey 2014 Aug 25. pp. 112.

2. Applied Technology Council, ATC-40. Seismic evaluation end retrofit of concrete building. Report No.SSC 96-01, Redwood City, CA, USA, November, 1996.

3. Federal Emergency Management Agency, FEMA-356. Prestandard and commentary for the seismic rehabilitation of buildings, Washington (DC) 2000.

4. Computers \& Structures Inc. . CSI analysis reference manual for SAP2000,

ETABS,andSAFEhttp://docs.csiamerica.com/manuals/misc/CSI\%2 0Analysis\%20Reference\%20Manual\%202011-12.pdf, 2011.

5. Inel $M$ and Ozmen H. B. Effects of plastic hinge properties in nonlinear analysis ofreinforcedconcretebuildings.Engineering.Structure.2006.https://d oi:10.1016/j.engstruct.2006.01.017 vol. 28, no. 11, pp. 1494-1502.

6. Zendaoui A., Kadid A., and Yahiaoui D. Comparison of Different Numerical Models of RC Elements for Predicting the Seismic Performance of Structures. International Journal of Concrete Structures and Material. 2016 Dec 1;10(4):461-78. https://doi 10.1007/s40069-016-0170-7.

7. Ladjinovic DJ., Raseta A., Radujkovic A., and Folic R. Prokic A. Comparison of Structural Models for Seismic Analysis of MultiStorey Frame Buildings, $15^{\text {th }}$ World Conference of Earthquake Engineering Lisbon Port, 2012.

8. Vecchio F. J. and Emara M. B. Shear Deformations in Reinforced Concrete Frames. ACI Structural Journal, 1992 Jan 1;89(1):46-56.

9. LSTC. LS-DYNA Keyword User's Manual. Livermore software Technology Corporation, California, 2016.

10. Hallquist J. O., LS-DYNA theory manual, Livermore software Technology Corporation 2006, p6.

11. Park R, Paulay T. Reinforced concrete structures. New York: John Wiley \& Sons; 1975. 769 pages.

12. ACI Standard, Building Code Requirements for Structural Concrete and Commentary on Building Code Requirements for Structural Concrete (ACI 318 R-14), Texas, 2014.

13. Telford T. CEB-FIP Model Code 1990 Design Code.

14. IS 456:2000, Indian Standard Code of Practice for Plain And Reinforced Concrete ,(Fifth Revision), Bureau of Indian Standard, New Delhi.2000. vol. 37, no. July, 1940, doi: 10.14359/8543.

15. Kwak HG, Kim, SP. Nonlinear analysis of RC beams based on moment-curvature relation. Computers \& Structures. 2002. Mar1; 80(7-8), 615-628.doi:10.1016/s0045-7949(02)00030-5.

16. Panandikar N, Narayan KB. Sensitivity of pushover curve to material and geometric modelling - an analytical investigation. In Structures 2015 Jun 1 (Vol. 2, pp. 91-97). Elsevier.

17. Tavio T, Wimbadi I, Negara AK, Tirtajaya R. Effects of confinement on interaction diagrams of square reinforced concrete columns. Civil Engineering Dimension. 2009 Jun 25;11(2):78-88.

18. Konstantinidis D, Kappos KJ, and Izzuddin BA. Analytical model for unconfined and confined high strength concrete under cyclic loading. in $13^{\text {th }}$ World Conference on Earthquake Engineering, 2004 Aug 1(No. 2064).

19. Mander JB, Priestley MJ, Park R. Theoretical stress-strain model for confined concrete. Journal of structural engineering. 1988 Aug;114(8):1804-26.
20. Kent DC., and Park R. Flexural members with confined concrete. Journal of Structural Division. 1971 Jul

21. Cusson, D., and Paultre P. Stress-Strain Model for confined HighStrength concrete," Journal of Structural Engineering ASCE. 1995. Mar;121(3):468-77.

22. Suzuki M, Akiyama M, Hong KN, Cameron ID, Wang WL. Stressstrain model of high-strength concrete confined by rectangular ties. In13 ${ }^{\text {th }}$ World Conference on Earthquake Engineering 2004 Aug 1.

23. Park R., Priestly M.J, and Gill WD. Ductility of Square Confined Concrete Columns. 1982. ASCE Journal of Structural Division.1982. Apr;108(4):929-50.

24. Sunitha P, Goswami R, Murty CV. Idealized bilinear momentcurvature curves of RC sections for pushover analysis of RC frame buildings. The Indian Concrete Journal. 2016 Apr;90(4):43-54.

25. CP 110. British code of practice,PART 1, 1972.

26. Zhao X., Wu Y. F., Leung A. Y., and Lam H. F. Plastic hinge length in reinforced concrete flexural members, Procedia Engineering.2011 Jan 1;14:1266-74., The Twelfth East Asia-Pacific Conference on Structural Engineering and Construction. https://doi:10.1016/j.proeng.2011.07.159pp. 1266-1274.

27. Mendis P. Plastic hinge lengths of normal and high-strength concrete in flexure. Advances in structural engineering. 2002 Oct;4(4):18995.https://doi.org/10.1260/136943301320896651, vol. 4, no. 4, pp. $189-195$.

28. I.C.E. Research Committee, Ultimate Load Design of Concrete Structures,Proceeding of the Institution of Civil Engineers. 1962. https://doi.org/10.1680/iicep.1962.05093 1962, pp. 399-442.

29. Priestley MN, Benzoni G. Seismic Performance of Circular Columns with Low Longitudinal Reinforcement Ratios. ACI Structural Journal. 1996. Jul 1;93(4):474-85.

30. Rajvi SR, Saatcioglu M. Analysis and Design of Concrete Column for Confinement. Earthquake Spectra. 1999 Nov;15(4):791-811. https://doi.org/10.1193/1.1586072.

31. Paulay T. and Priestley MN. Seismic Design of Reinforced Concrete and Masonry Structures. John Wiley \& Sons, Inc., 1992.

32. Sheikh SA, Khoury SS. Confined concrete columns with stubs. ACI Structural Journal. 1993 Jul 1;90:414.

33. Rao AR, Ramanjaneyulu K, editors. Recent Advances in Structural Engineering, Volume 2: Select Proceedings of. Springer; 2018 Aug 1.

34. Department of Urban Development and Building Construction. Nepal National Building Code, NBC 105:1994 Seismic Design of Buildings in Nepal.

35. IS 1893 (Part 1): 2002 Criteria for earthquake resistant design of structures General Provisions and Buildings (Fifth Revision), Bureau of Indian Standard, New Delhi, 2002. Vol. 1, No. 5.

36. Mwafy AM, Elnashai AS. Static pushover versus dynamic collapse analysis of RC buildings. Engineering Structures. 2001. May 1;23(5):407-24, https://doi: 10.1016/S0141-0296(00)00068-7.

37. Krawinkler H. and Seneviratna G. D. P. K. Pros and cons of a pushover analysis of seismic performance evaluation, Engineering $\begin{array}{llll}\text { Structures. } & 1998 & \text { Apr } & 1 ; 20(4-6): 452-64,\end{array}$ https://doi.org/10.1016/S0141-0296(97)00092-8 pp. 452-464.

38. Leslie R., The Pushover Analysis, explained in its Simplicity, in Proceedings of 2nd National Conference - RACE'13 at Saintgits College of Engineering, Kottayam. 2013.

39. Schwer L, Modeling Rebar. The Forgotten Sister in Reinforced Concrete Modeling (v2), in: $13^{\text {th }}$ International LS-DYNA Users Conference, 2014 June, Detroit, pp. 1-28. 
40. Murcia-Delso J, Benson Shing P. Bond-slip model for detailed finiteelement analysis of reinforced concrete structures. Journal of Structural Engineering. 2015 Apr 1;141(4):04014125. https://doi: 10.1061/(ASCE)ST.1943-541X.0001070. (United States), vol. 141, no. 4, pp. 1-10.

41. Malvar L. J., Crawford J. E., Wesevich J. W., and Simons D, A plasticity concrete material model for DYNA3D.," International Journal of Impact Engineering, 1997. Oct 1;19(9-10):847-73.

42. Crawford JE, Magallanes JM, Lan S, Wu Y. User's manual and documentation for release III of the $\mathrm{K} \& \mathrm{C}$ concrete material model in LS-DYNA. Technical Rep. TR-11-36. 2011 Nov;1.

43. Crawford JE, Wu Y, Choi HJ, Magallanes JM, Lan S. Use and validation of the release III K\&C concrete material model in LSDYNA. Karagozian \& Case, Glendale. 2012 Jul.

44. LSTC, LS-DYNA Keyword User's Manual - Volume II Material Models, vol. II. 2017.

45. Markovich N, Kochavi E, Ben-Dor G. An improved calibration of the concrete damage model. Finite Elements in Analysis and Design. 2011 Nov 1;47(11):1280-90.

46. Mardalizad A, Caruso M, Manes A, Giglio M. Investigation of mechanical behaviour of a quasi-brittle material using Karagozian and Case concrete (KCC) model. Journal of Rock Mechanics and Geotechnical Engineering. 2019 Dec 1;11(6):1119-37.
47. Wu Y, Crawford JE, Lan S, Magallanes JM. Validation studies for concrete constitutive models with blast test data. InProc., $13^{\text {th }}$ Int LS-DYNA® Users Conf., LSTC, Livermore, CA 2014 Jun.

48. Magallanes JM, Wu Y, Malvar LJ, Crawford JE. Recent improvements to release III of the K\&C concrete model. In $11^{\text {th }}$ international LS-DYNA Users conference 2010 Jun 6 (pp. 6-8). Livermore Software Technology Corporation Livermore, CA.

49. Jiang H, Zhao J. Calibration of the continuous surface cap model for concrete. Finite Elements in Analysis and Design. 2015 May 1;97:19.doi: 10.1016/j.finel.2014.12.002

50. Brannon RM, Fossum AF, Strack OE. Kayenta: theory and user's guide. Sandia Rep. 2009 Mar 1;2282:393-7.

51. Murray YD, Lewis BA. Numerical Simulation of Damage in Concrete. APTEK INC COLORADO SPRINGS CO; 1995 Nov 1.

52. Murray, Y.D., Users Manual for LS-DYNA Concrete Material Model 159, Report No. FHWA-HRT-05-062, Federal Highway Administration. 2007.

53. Murray, Y.D., Abu-Odeh, A., and Bligh, R., Evaluation of LSDYNA Concrete Material Model 159, FHWA-HRT-05-063, Federal Highway Administration, Turner-Fairbank Highway Research Center, McLean, Virginia, May, 2007 